\title{
Effect of lemongrass water extract supplementation on atherogenic index and antioxidant status in rats
}

\author{
NUNTIYA SOMPARN ${ }^{1 *}$ \\ SUPHAKET SAENTHAWEEUK ${ }^{1}$ \\ JARINYAPORN NAOWABOOT ${ }^{1}$ \\ ATCHARAPORN THAEOMOR ${ }^{2}$ \\ VEERAPOL KUKONGVIRIYAPAN ${ }^{3}$ \\ ${ }^{1}$ Department of Preclinical Science \\ Faculty of Medicine, Thammasat \\ University, Rangsit Campus \\ PathumThani, Thailand 12120 \\ ${ }^{2}$ School of Preclinical Science, Institute of \\ Science, Suranaree University of Technology \\ Nakhon Ratchasima, Thailand 30000 \\ ${ }^{3}$ Department of Pharmacology, Faculty \\ of Medicine, Khon Kaen University, Khon \\ Kaen, Thailand 40002
}

Accepted January 8, 2018

Published online February 6, 2018

\begin{abstract}
Cymbopogon citratus (DC) Stapf., commonly known as lemongrass, possesses strong antioxidant and cardiotonic properties. Lemongrass water extract contains several polyphenolic compounds including gallic acid, isoquercetin, quercetin, rutin, catechin and tannic acid. Rutin, isoquercetin catechin and quercetin are the flavonoids most abundantly found in the extract. The extract significantly decreased total cholesterol, low-density lipoprotein and atherogenic index in rats after treatment $(p<0.05)$. Expression of genes and protein of sterol regulatory element binding protein-1c (SREBP1c) and HMG-CoA reductase (HMGR) was also lowered significantly in treated groups $(p<0.05)$. Moreover, serum antioxidant capacity increased in treated rats in comparison with untreated ones $(p<0.05)$ and was associated with decreased serum lipid peroxidation.
\end{abstract}

Keywords: Cymbopogon citratus, lipid profile, antioxidant, SREBP1c, HMG-CoA reductase

High consumption of vegetables containing phytochemicals with antioxidant properties seems to be a protective factor against atherosclerosis (1). Treatment with statins, inhibitors of HMG-CoA reductase (HMGR), results in inhibition of endogenous cholesterol synthesis and is associated with regression of coronary atherosclerosis when LDL is substantially reduced and HDL is increased (2). However, plasma lipoprotein regulation is a complex process. Besides HMGR expression, the sterol regulatory element binding protein-1c (SREBP1c) is one of the major transcriptional regulators that induce key lipogenic enzymes to promote lipogenesis in the liver. Inhibition of SREBP1 could potentially improve hypertriglyceridemia and hepatic steatosis outcomes (3).

Cymbopogon citratus (DC) Stapf. (Poaceae), lemongrass, is a widely used herb in tropical countries. Lemongrass is used as a flavoring agent in food. In addition, lemongrass tea is a refreshing beverage. Phytochemicals such as flavonoids, alkaloids, volatile and nonvolatile terpenoids, carotenoids and tannins have been identified from lemongrass (4). A recent study showed that flavonoid consumption is associated with a lower mortality risk

\footnotetext{
*Correspondence; e-mail: nuntiya_tom@hotmail.com
} 
of cardiovascular diseases and that even relatively small amounts of flavonoid-rich nourishments might be beneficial (5). Although some studies address the health benefits and metabolic effects of lemongrass extract, there are few studies of the prolonged consumption of the extract in healthy subjects. Therefore, this study was aimed at investigating the effects of the consumption of lemongrass aqueous extract (CCW) on the atherogenic index (AI) and antioxidant status in rats. Water extract was investigated because lemongrass decoction is the most commonly used form.

\section{EXPERIMENTAL}

\section{Plant material}

The plant was cultivated in Khon Kaen Province, Thailand, and was collected in November 2014. Its botanical identity was determined and authenticated by a taxonomist. A voucher specimen is deposited in the herbarium of the Faculty of Pharmaceutical Sciences, Prince of Songkla University, Songkla Province, Thailand.

\section{Extraction}

Collected plant material (whole plants) was washed thoroughly with clean water, cut into small pieces, boiled in distilled water (1 $\mathrm{g}$ of plant material in $10 \mathrm{~mL}$ of water) for $1 \mathrm{~h}$ and then filtered. Filtrates were concentrated using a rotary vacuum evaporator and subsequently lyophilized. Water extract yield was $4.0 \%$. The extract was stored at $-80{ }^{\circ} \mathrm{C}$ until use.

\section{Analyses of phytochemicals in CCW extract}

Total phenolic content was analyzed using the Folin-Ciocalteu method (6). Gallic acid was used as a reference standard and the results were expressed as gallic acid equivalents (GAE).

Total flavonoids were determined using aluminum chloride according to a previously published method (7), using catechin as a standard. The results were expressed as catechin equivalents (CE).

Phenolic compounds in the CCW extract were further quantitated by high-performance liquid chromatography with diode array detection and a mass spectrometry detector (HPLC-DAD/MSD) (8). Briefly, phenolic compounds were separated using an Agilent 1100 series HPLC system (Agilent Technologies, Germany), equipped with a LiChroCART Stainless Steel Purospher STAR RP-18E column $(150 \mathrm{~mm} \times 4.6 \mathrm{~mm}$, particle size $5 \mu \mathrm{m})$ (Merck, Germany) and a diode array detector recording at 270, 330, 350 and $370 \mathrm{~nm}$. The binary mobile phase consisted of acetonitrile (solvent A) and $10 \mathrm{mmol} \mathrm{L} \mathrm{m}^{-1}$ ammonium formate buffer, $\mathrm{pH} 4$, with formic acid (solvent B). Separation of compounds was carried out with a gradient (0-5 min B $100 \%, 5-10$ min A 0-20\%, 10-20 min A 20\%, 20-60 min A

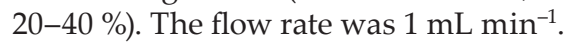

In addition to identification of compounds by comparison with the reference standard retention time $\left(t_{\mathrm{R}}\right)$, mass spectrometry detection was carried out using an Agilent Mass Selective Detector system (Agilent Technologies, USA) to confirm and identify the components in unresolved chromatographic peaks. Briefly, nitrogen was used as the nebulizing 
gas with a flow rate of $13 \mathrm{~L} \mathrm{~min}^{-1}$ at $320^{\circ} \mathrm{C}$. Capillary voltages were set at $4000 \mathrm{~V}$ (positive) and $3000 \mathrm{~V}$ (negative). A scan time of $0.2 \mathrm{~s}$ with $\mathrm{m} / \mathrm{z}$ range of 100-700 was employed.

All standard compounds were purchased from Sigma-Aldrich (USA). Data acquisition was performed with Chemstation software A.08.03 (Agilent Technologies, USA). CCW extract was analyzed against phenolic standards. Standard calibration curves were established by plotting the areas of peaks against different concentrations. Limit of detection $(L O D)$ was estimated based on signal-to-noise ratio of 3 being considered as acceptable.

\section{1,1-Diphenyl-2-picrylhydrazyl (DPPH) radical scavenging assay}

Radical scavenger efficiency of CCW extract was evaluated using the DPPH radical scavenging activity assay following the method previously described (9).

\section{Experimental animals and design}

Thirty healthy adult male Sprague-Dawley rats were supplied by the National Animal Center, Mahidol University, Thailand. Animals were allowed ad libitum access to standard rat chow and water. They were divided into five groups of six rats each. The group I (control group) animals were orally administered vehicle solution (distilled water) for 30 days. The animals in groups II-IV were orally administered CCW extract, which was dissolved in distilled water, at doses of 250, 500 and $1,000 \mathrm{mg} \mathrm{kg}^{-1} \mathrm{bm}$ per day, resp., for 30 days. The animals in group $\mathrm{V}$ were orally administered simvastatin dissolved in distilled water at a daily dose of $10 \mathrm{mg} \mathrm{kg}^{-1} \mathrm{bm}$.

The animal procedure of this study was approved by the Animal Research Committee of Thammasat University, Thailand. All institutional and national rules for the care and utilization of laboratory animals were followed.

\section{Antioxidant status and lipid peroxidation in rats}

The total antioxidant capacity (TAC) in serum was assessed with Abcam's Total Antioxidant Capacity Assay Kit (ab65329, Abcam, UK) as per the manufacturer's instructions. Serum catalase (CAT) and superoxide dismutase (SOD) activities were assessed using a catalase assay kit and a superoxide dismutase assay kit (Cayman Chemical Company, USA), resp., according to the manufacturer's instructions. Malondialdehyde (MDA), the marker of lipid peroxidation, was measured in serum as a thiobarbituric acid reactive substance (TBAR) following a previously reported method (10).

\section{Body/organ masses and biochemical parameters}

Masses of animals and internal organs, including the heart, kidneys, liver and pancreas, were measured at the end of the experiment. Blood was taken from rat's heart by cardiac puncture. Serum was centrifuged at $2,000 \mathrm{~g}$ at $4{ }^{\circ} \mathrm{C}$ for $10 \mathrm{~min}$. Biochemical markers of liver and kidney function, including aspartate aminotransferase (AST) and alanine aminotransferase (ALT), blood urea nitrogen (BUN) and serum creatinine (Cr), as well as lipid profiles, including triglyceride (TG), total cholesterol (TC), high density lipoprotein (HDL) and low density lipoprotein (LDL), were measured in the laboratory unit of the Thammasat University Hospital, Pathumthani Thailand. 


\section{Gene expression}

Total RNA was extracted from the liver tissue using the TRIzol ${ }^{\circledR}$ reagent, following the manufacturer's instructions (Thermo Fisher Scientific, USA ). The ImProm-II ${ }^{\mathrm{TM}}$ Reverse Transcription System (Promega Corporation, USA) was used for total RNA reverse transcription. PCR amplification was performed using specific primers for the SERBP1c, HMGR and the internal control, which was glyceraldehyde 3-phosphate dehydrogenase (GAPDH). Primer sequences were as follows: $i$ ) HMGR forward primer 5'-CATGCTGCCAACATCGTCA-3' and reverse primer 5'-CCCACATTCTGTGCTGCATC-3'(11), ii) SERBP1c forward primer 5'-CCTGGTGGTGGGCACTGA-3' and reverse primer 5'-GTGCTGTAAGAAGCGGATGTAGTC-3', and iii) GADPH forward primer 5'-TGTTCTAGAGACAGCCGCATCTT-3' and reverse primer 5'-CCGACCTTCACCATCTTGTCTAT-3' (12). Gene expression was measured using real-time fluorescence PCR. It was carried out with ABI StepOnePlus (Applied Biosystems, USA) using SsoFast ${ }^{\mathrm{TM}}$ EvaGreen ${ }^{\circledR}$ Supermix with low ROX (Bio-Rad, USA). Negative controls (template with deionized water) were included in each run. Amplification data were collected and analyzed with StepOne software V2.2.2 (Applied Biosystems).

\section{Western blot analysis}

Western blot analysis was used to determine the protein expression of SERBP1c or HMGR and $\beta$-actin. Fresh liver was washed with ice-cold phosphate-buffered saline (PBS), homogenized with cell lysis buffer (Cell Signaling Technology, USA) with the addition of protease inhibitor cocktail M221 (Amresco, USA) at $4{ }^{\circ} \mathrm{C}$. After vigorous vortex mixing and centrifuging, the supernatant was collected and the protein content was determined. Sample protein was mixed with sodium dodecyl sulfate (SDS) loading buffer and subjected to electrophoretic separation. The bands were blotted onto a polyvinylidene fluoride (PVDF) membrane. After being blocked with $5 \%(\mathrm{~m} / \mathrm{V})$ skimmed milk powder in PBS containing $0.1 \%$ Tween 20 at room temperature for $1 \mathrm{~h}$, the PVDF membranes were incubated overnight with primary antibodies [mouse monoclonal anti-SERBP1c (sc-365513), rabbit polyclonal anti-HMGR (sc-33827), and mouse polyclonal anti- $\beta$-actin (sc-8432) antibodies] in PBS at $4{ }^{\circ} \mathrm{C}$. After being washed with PBS, the blots were incubated for $1 \mathrm{~h}$ at room temperature with horseradish peroxidase (HRP)-labeled secondary antibodies (anti-rabbit IgG-HRP, sc-2004, anti-mouse IgG-HRP, sc-2005, Santa Cruz Biotechnology, USA). After incubation, the blots were washed with PBS and processed for chemiluminescence detection using an enhanced chemiluminescence (ECL) reagent (Amersham ${ }^{\mathrm{TM}}$ ECL $^{\mathrm{TM}}$ prime western blotting detection reagent, GE Healthcare, USA). Densities of each specific protein bands were visualized and analyzed with the aid of Image Studio version 2.1 software (Odyssey Fc Imaging System, LI-COR ${ }^{\circledR}$ Biosciences, USA).

\section{Histopathological examination}

After treatment with CCW extract (at doses of 250, 500 and 1,000 $\mathrm{mg} \mathrm{kg}^{-1} \mathrm{bm}_{\text {per day) }}$ or simvastatin (at a dose of $10 \mathrm{mg} \mathrm{kg}^{-1} \mathrm{bm}$ per day) for 30 days, the animals were sacrificed by isoflurane euthanasia. The tissues (rat liver and aorta) were immediately fixed in $4 \%$ paraformaldehyde and embedded in paraffin. A series of $5-\mu \mathrm{m}$ thick sections was stained with hematoxylin-eosin (H\&E). The H\&E stained slides were examined under a photomicroscope. 


\section{Statistical analysis}

All data were expressed as mean \pm SEM. Significant differences $(p<0.05)$ between experimental groups were analyzed using the analysis of variance (ANOVA) with Duncan post-hoc test. ANOVA on the rank test was used for non-parametric analysis.

\section{RESULTS AND DISCUSSION}

\section{Phytochemical analysis and antioxidant property of CCW extract}

According to phytochemical screening, the CCW extract contained flavonoids, $496 \pm$ $85 \mathrm{mg} \mathrm{kg}^{-1} \mathrm{CE}$, and phenolic compounds, $402 \pm 13 \mathrm{mg} \mathrm{kg}^{-1} \mathrm{GAE}$. The DPPH assay showed that $920 \pm 23 \mathrm{mg} \mathrm{mL}^{-1}$ extract induced $50 \%$ free radical scavenging inhibition.

At least six polyphenolic compounds were identified in CCW extract, including gallic acid $\left(t_{R}=6.93 \mathrm{~min}\right)$, isoquercetin $\left(t_{R}=16.50 \mathrm{~min}\right)$, quercetin $\left(t_{R}=33.94 \mathrm{~min}\right)$, rutin $\left(t_{R}=15.36\right.$ $\mathrm{min})$, catechin $\left(t_{\mathrm{R}}=12.57 \mathrm{~min}\right)$ and tannic acid $\left(t_{\mathrm{R}}=12.89 \mathrm{~min}\right)$ (Fig. 1). Along with retention

a)

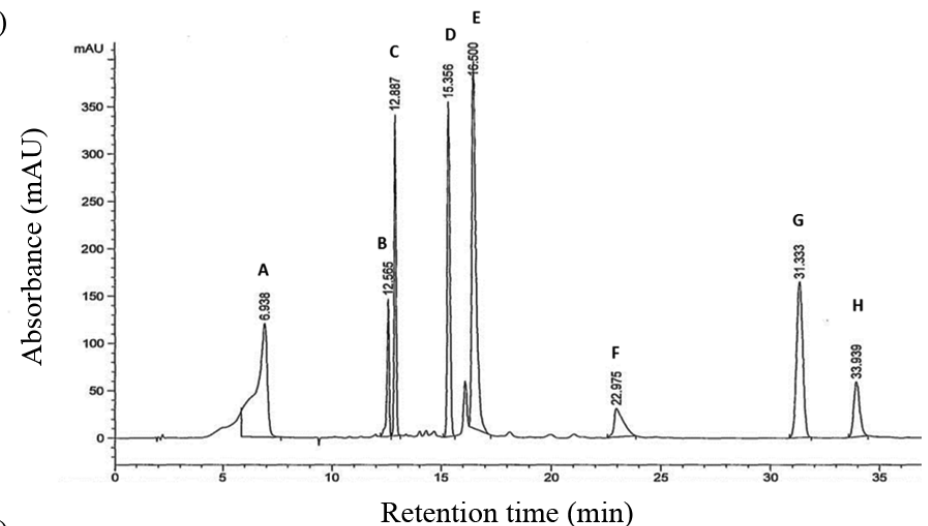

b)

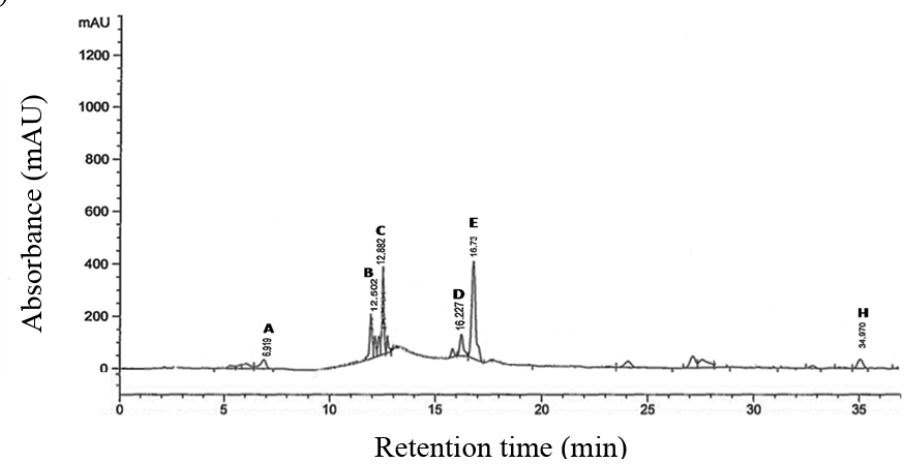

Fig. 1. HPLC-DAD chromatograms of: a) standard mixture: A - gallic acid, B - catechin, $\mathrm{C}-$ tannic acid, D - rutin, E - isoquercetin, $\mathrm{F}$ - hydroquinone, $\mathrm{G}$ - eriodictyol, $\mathrm{H}$ - quercetin; b) representative sample of CCW. The diode array detector was set at $270 \mathrm{~nm}$. 
N. Somparn et al.: Effect of lemongrass water extract supplementation on atherogenic index and antioxidant status in rats, Acta Pharm. 68 (2018) 185-197.

Table I. Selective ion monitoring of the target, retention time and polyphenolic composition of CCW extract

\begin{tabular}{lccc}
\hline Compound & $\begin{array}{c}\text { Retention time } \\
(\mathrm{min})\end{array}$ & $\begin{array}{c}\text { Characteristic ions } \\
(\mathrm{m} / \mathrm{z})\end{array}$ & $\begin{array}{c}\text { Amount } \\
\left(\mathrm{mg} \mathrm{kg}^{-1} \text { dry extract }\right)\end{array}$ \\
\hline Gallic acid & 6.93 & 188,209 & 474.66 \\
Catechin & 12.57 & $185,329,503,649$ & 898.64 \\
Tannic acid & 12.89 & $185,329,503,649$ & 432.43 \\
Rutin & 15.36 & $185,329,503,649$ & 1032 \\
Isoquercetin & 16.5 & $185,329,503,649$ & 989.03 \\
Hydroquinone & 22.97 & $289,327,341$ & $\mathrm{ND}^{\mathrm{a}}$ \\
Eriodictyol & 31.33 & $289,327,341$ & $\mathrm{ND}^{\mathrm{a}}$ \\
Quercetin & 33.94 & $289,327,341$ & 738.81 \\
\hline
\end{tabular}

ND - not detected, ${ }^{\text {a }}$ Limit of detection: $10 \mathrm{mg} \mathrm{kg}^{-1}$.

time, the resulting product ion from mass spectrometry detection was used as a fingerprint of each compound (Table I). These results suggest that CCW extract is a phenolicsrich extract with rutin, isoquercetin, catechin and quercetin as most abundant.

\section{General toxicity of CCW extract}

For clinical signs of toxicity of CCW extract after multiple doses, the general appearance and behavior of animals were observed. In this study, there were no differences in general appearance and behavior of animals between the groups after multiple doses of CCW compared with the normal control. No statistically significant differences were found between body mass changes and the mass of vital organs (liver, kidney and heart) among the groups (Table II). Histopathological examination was performed to show no abnormality in the liver of any of the animals (Fig. 2a). Serum AST, ALT, BUN and Cr levels

Table II. Relative organ masses of rats after 30 days of CCW treatment

\begin{tabular}{lccccc}
\hline Group & $\begin{array}{c}\text { Body mass bm } \\
(\mathrm{g})\end{array}$ & $\begin{array}{c}\text { Heart } \\
(\mathrm{g} \text { per } 100 \mathrm{~g} \mathrm{bm})\end{array}$ & $\begin{array}{c}\text { Kidney } \\
(\mathrm{g} \text { per 100 g bm) }\end{array}$ & $\begin{array}{c}\text { Pancreas } \\
(\mathrm{g} \text { per 100 g bm) }\end{array}$ & $\begin{array}{c}\text { Liver } \\
(\mathrm{g} \text { per 100 g bm })\end{array}$ \\
\hline Control & $373 \pm 17$ & $0.38 \pm 0.01$ & $0.70 \pm 0.03$ & $0.30 \pm 0.02$ & $3.40 \pm 0.33$ \\
CCW 250 & $364 \pm 6$ & $0.39 \pm 0.01$ & $0.73 \pm 0.03$ & $0.34 \pm 0.03$ & $3.29 \pm 0.15$ \\
CCW 500 & $374 \pm 11$ & $0.42 \pm 0.06$ & $0.78 \pm 0.03$ & $0.37 \pm 0.04$ & $3.33 \pm 0.23$ \\
CCW 1000 & $349 \pm 19$ & $0.34 \pm 0.06$ & $0.73 \pm 0.02$ & $0.38 \pm 0.03$ & $3.28 \pm 0.28$ \\
Simvastatin & $347 \pm 12$ & $0.40 \pm 0.06$ & $0.72 \pm 0.03$ & $0.36 \pm 0.02$ & $3.26 \pm 0.18$ \\
\hline
\end{tabular}

Dosing regime over 30 days: CCW 250, CCW 500, CCW 1000 rats fed CCW extract: 250, 500 or $1000 \mathrm{mg} \mathrm{kg}^{-1}$ bm daily, resp.; simvastatin rats: $10 \mathrm{mg} \mathrm{kg}^{-1} \mathrm{bm}$ daily, control group: vehicle solution.

Mean $\pm \operatorname{SEM}(n=6)$. 
a)
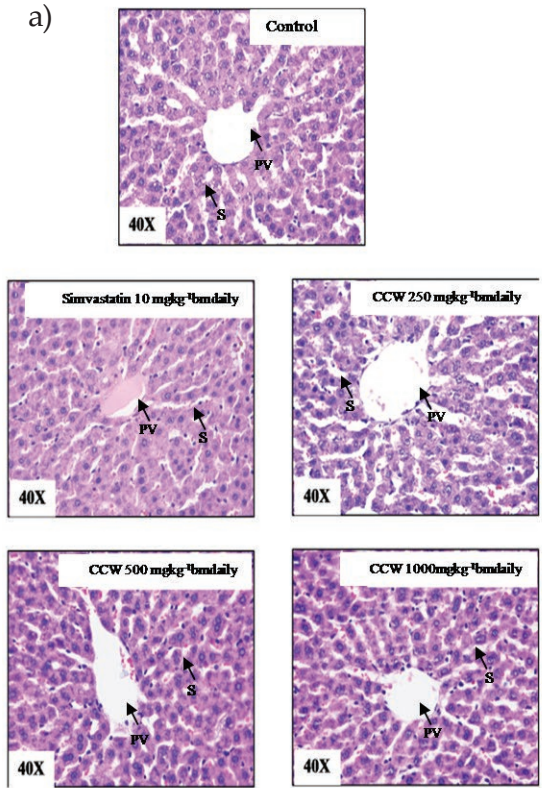

b)
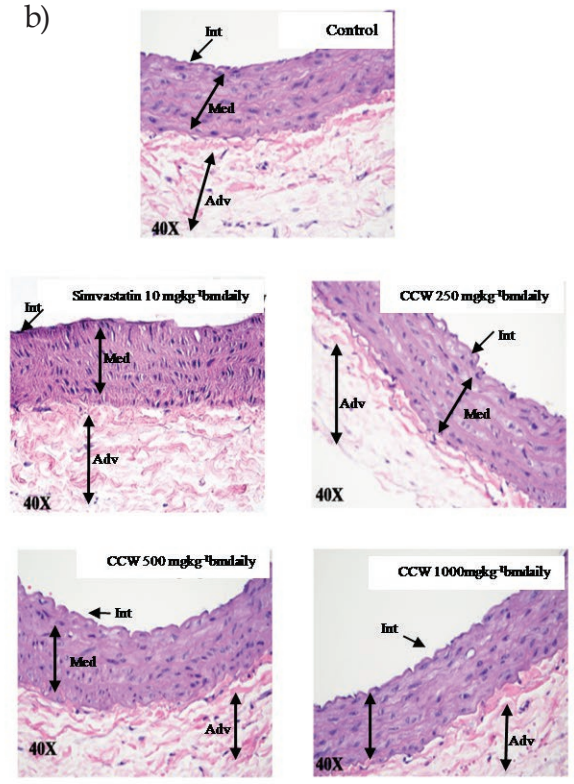

Fig. 2. Histological section of: a) liver and b) rats' aorta after treatment. Representative slides of corresponding groups. Adv - tunica adventitia, Int - tunica intima, Med - tunica media, PV - branch of portal vein, $\mathrm{s}-$ sinusoid.

remained unchanged (Table III). Thus, liver and kidney functions were not affected by the CCW administration. These results indicated that CCW water extract administration was safe at daily doses up to $1,000 \mathrm{mg} \mathrm{kg}^{-1}$ for at least 30 days.

Table III. Biochemical parameters in rat serum after 30 days of CCW treatment

\begin{tabular}{lcccc}
\hline Group & AST & ALT & BUN & Cr \\
\hline Control & $\left(\mathrm{U} \mathrm{L}^{-1}\right)$ & $\left(\mathrm{U} \mathrm{L}^{-1}\right)$ & $(\mathrm{mg}$ per 100 mL) & $(\mathrm{mg}$ per 100 mL) \\
CCW 250 & $20.33 \pm 0.61$ & $0.38 \pm 0.07$ & $194.54 \pm 15.08$ & $65.50 \pm 3.42$ \\
CCW 500 & $19.33 \pm 0.80$ & $0.43 \pm 0.62$ & $193.83 \pm 8.98$ & $77.67 \pm 8.45$ \\
CCW 1000 & $21.50 \pm 1.98$ & $0.38 \pm 0.09$ & $196.83 \pm 24.01$ & $64.17 \pm 2.75$ \\
Simvastatin & $18.00 \pm 1.59$ & $0.39 \pm 0.04$ & $191.50 \pm 13.00$ & $58.83 \pm 2.87$ \\
\hline
\end{tabular}

AST - aspartate aminotransferase, ALT - alanine aminotransferase, BUN - blood urea nitrogen, $\mathrm{Cr}$ - creatinine Dosing regime over 30 days: CCW 250, CCW 500, CCW 1000 rats fed CCW extract: 250, 500 or $1000 \mathrm{mg} \mathrm{kg}^{-1}$ bm daily, resp.; simvastatin rats: $10 \mathrm{mg} \mathrm{kg}^{-1} \mathrm{bm}$ daily, control group: vehicle solution.

Mean $\pm \operatorname{SEM}(n=6)$. 


\section{Effects of CS extract on lipid peroxidation and antioxidant status}

In this study, the basal lipid peroxidation in serum was decreased in rats treated with CCW extract in a dose-dependent manner (Table IV). The antioxidant activities of SOD and CAT were significantly induced by CCW treatment at all doses (Table IV). Serum TAC was found to be slightly increased compared to the control group (Table IV) $(p<0.05)$. An increase in the SOD, CAT and diminished lipid peroxidation levels was observed in rutin and quercetin pretreated rats (13). Furthermore, a significant decrease in the level of MDA, along with increased CAT and SOD activities, in catechin-treated rats was (14). Since rutin, isoquercetin, catechin and quercetin were the major phenolic compounds present in CCW, the modulation of SOD, CAT and lipid peroxidation in the CCW-treated group could potentially be due to the effect of these compounds.

Table IV. Effect of CCW extract on lipid peroxidation and antioxidant parameters

\begin{tabular}{lcccc}
\hline Group & $\begin{array}{c}\text { MDA } \\
\left(\mathrm{mmol} \mathrm{L}{ }^{-1}\right)\end{array}$ & $\begin{array}{c}\mathrm{SOD} \\
\left(\mathrm{U} \mathrm{mL}^{-1}\right)\end{array}$ & $\begin{array}{c}\mathrm{CAT} \\
\left(\mathrm{U} \mathrm{mL}^{-1}\right)\end{array}$ & $\begin{array}{c}\text { TAC } \\
\left(\mathrm{mmol} \mathrm{L}^{-1} \text {, Trolox }\right. \\
\text { equivalents })\end{array}$ \\
\hline Control & $76.66 \pm 0.95$ & $0.036 \pm 0.01$ & $3.36 \pm 0.01$ & $1.50 \pm 0.09$ \\
CCW 250 & $64.45 \pm 1.29^{*}$ & $0.038 \pm 0.01$ & $4.25 \pm 0.11^{*}$ & $1.66 \pm 0.07$ \\
CCW 500 & $56.66 \pm 0.71^{*}$ & $0.041 \pm 0.03^{*}$ & $4.22 \pm 0.05^{*}$ & $1.70 \pm 0.16$ \\
CCW 1000 & $50.01 \pm 0.69^{*}$ & $0.066 \pm 0.01^{*}$ & $4.84 \pm 0.03^{*}$ & $1.82 \pm 0.04^{*}$ \\
Simvastatin & $57.51 \pm 1.69^{*}$ & $0.039 \pm 0.01^{*}$ & $4.24 \pm 0.03^{*}$ & $1.62 \pm 0.08$ \\
\hline
\end{tabular}

CAT - catalase, MDA - malondialdehyde, SOD - superoxide dismutase, TAC - total antioxidant capacity

Dosing regime over 30 days: CCW 250, CCW 500, CCW 1000 rats fed CCW extract: 250, 500 or $1000 \mathrm{mg} \mathrm{kg}^{-1}$ bm daily, resp.; simvastatin rats: $10 \mathrm{mg} \mathrm{kg}^{-1} \mathrm{bm}$ daily, control group: vehicle solution.

Mean $\pm \operatorname{SEM}(n=6)$.

Statistically significant difference compared with control: ${ }^{*} p<0.05$.

Table V. Effect of CCW extract on lipid status and atherogenic index

\begin{tabular}{lccccc}
\hline Group & TG & HDL & LDL & TC & $\begin{array}{c}\text { Atherogenic } \\
\text { index }\end{array}$ \\
\hline & $(\mathrm{mg}$ per $100 \mathrm{~mL})$ & $(\mathrm{mg}$ per $100 \mathrm{~mL})$ & $(\mathrm{mg}$ per $100 \mathrm{~mL})$ & $(\mathrm{mg}$ per $100 \mathrm{~mL})$ & $\log (\mathrm{TG} / \mathrm{HDL})$ \\
\hline Control & $79.44 \pm 8.66$ & $23.63 \pm 1.01$ & $29.37 \pm 8.96$ & $94.64 \pm 7.11$ & $0.60 \pm 0.06$ \\
CCW 250 & $67.50 \pm 13.66$ & $25.49 \pm 2.13$ & $28.61 \pm 1.64$ & $86.02 \pm 7.22$ & $0.32 \pm 0.14^{*}$ \\
CCW 500 & $65.88 \pm 7.47$ & $26.15 \pm 3.60$ & $23.28 \pm 4.67^{*}$ & $78.13 \pm 4.13^{*}$ & $0.20 \pm 0.10^{*}$ \\
CCW 1000 & $67.30 \pm 12.81$ & $26.54 \pm 2.65$ & $22.78 \pm 2.94^{*}$ & $79.61 \pm 6.82^{*}$ & $0.13 \pm 0.10^{*, * *}$ \\
Simvastatin & $61.14 \pm 5.16^{*}$ & $26.76 \pm 2.41$ & $19.76 \pm 2.23^{* * * *}$ & $75.33 \pm 5.13^{*}$ & $0.12 \pm 0.12^{*, * *}$ \\
\hline
\end{tabular}

HDL - high density lipoprotein, LDL - low density lipoprotein, TC - total cholesterol, TG - triglyceride

Dosing regime over 30 days: CCW 250, CCW 500, CCW 1000 rats fed CCW extract: 250, 500 or $1000 \mathrm{mg} \mathrm{kg}^{-1}$ bm daily, resp.; simvastatin rats: $10 \mathrm{mg} \mathrm{kg}^{-1} \mathrm{bm}$ daily, control group: vehicle solution. Mean \pm SEM $(n=6)$.

Statistically significant difference: ${ }^{*} p<0.05$ (vs. control group); ${ }^{* *} p<0.05$ (vs. CCW 250 treated group). 
a)

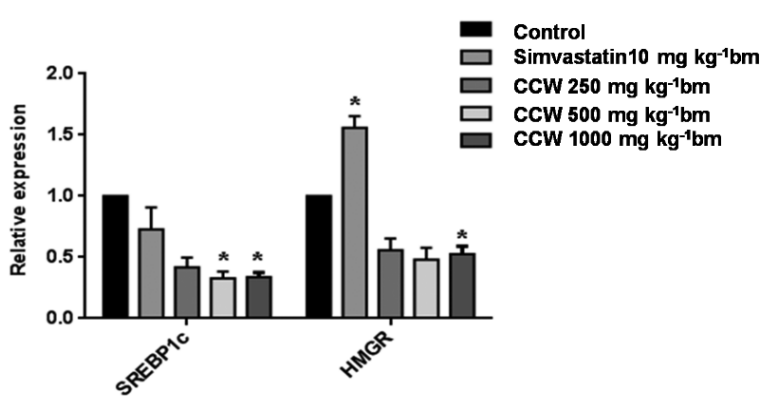

b) 1


3



2
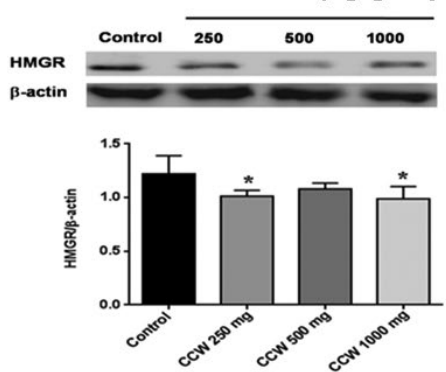

4
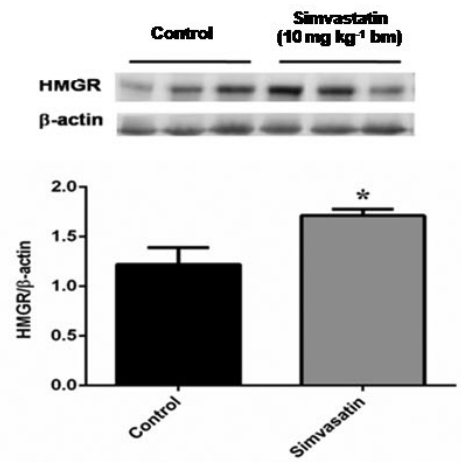

Fig. 3. a) Expression of hepatic SREBP1c and HMGR mRNA, and b) Western blot analysis of: SREBP1c ( 1 and 3 ) and HMGR (2 and 4) expression in rats; representative images. Each bar represents the mean \pm SEM, $n=6$. Statistically significant difference $v$ s. control: ${ }^{*} p<0.05$.

\section{Effects of CS extract on serum lipid profiles}

In addition to the antioxidant property, the serum TC and LDL concentrations in CCW-treated groups were found to decrease compared to those in the untreated group $(p<0.05)$, whereas the serum HDL level had a tendency to increase and TG level had a tendency to decrease ( $p=0.09$ and $p=0.08$, resp.) but still not significantly, whereas treatment 
with simvastatin dramatically decreased LDL concentration compared to the control and CCW-treated groups $(p<0.05)$. In particular, the administration of CCW and simvastatin significantly reduced the atherogenic index, the predictor of cardiovascular risk (15) compared to the control group $(p<0.05$, Table V). In addition, a histological study of the thoracic aorta was performed to assess the adaptive intima thickenings of the artery wall where atherosclerotic lesions are prone to develop. No changes were observed (Fig. 2b).

The present study demonstrated that the CCW extract had the ability to reduce serum TC and LDL levels. Some previous reports provided evidence of the flavonoid hypolipidemic effect and antioxidant properties, which are associated with their ability to decrease the plasma total cholesterol concentration and enhance the antioxidant system $(16,17)$. Influence of quercetin on the lipid profile and its anti-atherosclerotic effects have been reported recently (18). Catechin has been shown to up-regulate the LDL receptor and increase the clearance rate of cholesterol (19). Rutin was shown to decrease the levels of lipids in plasma and tissues in streptozotocin-induced diabetic rats (20). Moreover, rutin alone or in combination with lovastatin was reported to reduce the levels of total cholesterol and LDL in animals on a high-cholesterol diet (21). Isoquercetin was shown to decrease total cholesterol and triglycerides in diabetic mice and high-cholesterol diet-treated rabbits (22).

\section{Effects of CS extract consumption on lipid regulatory genes and proteins}

To investigate whether CCW reduced serum cholesterol due to inhibition of the expression of lipid regulatory genes and proteins, RNA and protein expression analyses of transcription factor and enzymes involved in lipid synthesis (SERBP1c and HMGR, resp.) were performed. Consistent with the decreased levels of serum TC and LDL, gene expressions of SREBP1c and HMGR were significantly reduced in all CCW-treated groups compared to the control group ( $p<0.05)$, as shown in Fig. 3a.

Moreover, protein expressions of SREBP1c and HMGR were also decreased after CCW treatment, as shown in Fig. 3b. Interestingly, HMGR protein and gene expressions were significantly increased in the simvastatin-treated group compared to the control $(p<0.05)$, as shown in Figs. 3a,b. However, treatment with simvastatin caused no significant change of SREBP1c gene and protein expression. In our study, the effects of CCW and simvastatin on SREBP1c and HMGR were different. Simvastatin, a competitive inhibitor of HMGR, caused induction of HMGR gene expression, but CCW did not exert this effect. Thus, we speculate that CCW may not act as a competitive inhibitor of the enzyme HMGR like simvastatin (23). Its efficacy may depend on individual characteristics of active compounds.

The findings that CCW extract decreased gene and protein expression of SREBP1c and HMGR were in agreement with previous reports. For example, quercetin-induced LDL gene expression accompanied with an increase in nuclear SREBPs and decreased HMGR activity has been reported (24). In addition, rutin was shown to inhibit oleic acid-induced lipid accumulation via inhibition of HMGR transcription in HepG2 cells (25). Administration of $1 \%$ green tea, an excellent source of catechin, to rat for 6 months showed a reduction in the gene expression of SREBP1c (26). Moreover, luteolin found in lemongrass has been reported (27). This compound exhibited a lipid-lowering potential by significant down-regulation of SREBP1c and fatty acid synthase gene expression in animal models (28). Thus, the effects of CCW extract on gene and protein expression of SREBP1c and HMGR might be mediated, at least in part, by rutin, quercetin and catechin, which we 
found in the extract, or, even more, by more active compounds such as luteolin found in the plant by other authors $(27,28)$.

Drugs of the statin group inhibit endogenous cholesterol production by competitive inhibition of the enzyme HMGR (23). When rats were fed diets containing statins, an adverse increase of HMGR mRNA and protein was observed. However, feeding rats with a diet containing $0.04 \%$ atorvastatin showed induction of HMGR mRNA and protein expression but the apparent HMGR activity was not increased to the extent of the protein levels (29). Moreover, in a rodent model of the metabolic syndrome (MetS rats), statin treatment also increased the expression of genes regulated by SREBP1c, leading to up-regulation of intestinal lipid secretion (30). In agreement with additional studies, we found that rats treated with simvastatin enhanced HMGR gene and protein expression. However, unlike the MetS rats, the healthy rats treated with simvastatin did not exert a significant change in SREBP1c gene and protein expression. This finding suggests that alternative mechanisms may be involved in the lipid-lowering effect of statins in distinct animal models.

\section{CONCLUSIONS}

Our study utilized a water extract of CCW that comprised rutin, isoquercetin, catechin and quercetin as major polyphenolic compounds. In addition to the antioxidant property, CCW exerted an ability to reduce the atherogenic index, serum TC and LDL levels. Its lipid-lowering effects were mediated, at least in part, by influencing the gene and protein expression of SREBP1c and HMGR. Therefore, the results support the assumption that CCW consumption reduces the atherogenic index and enhances the serum antioxidant capacity, thereby indicating its potential in reducing the risks of cardiovascular diseases. Further efforts are required to isolate active compounds from the extract as well as to elucidate their mechanisms of action.

Acronyms, abbreviations, symbols. - AI - atherogenic index, AST - aspartate aminotransferase, ALT - alanine aminotransferase, BUN - blood urea nitrogen, CAT - catalase, CCW - lemongrass aqueous extract, $\mathrm{CE}$ - catechin equivalents, $\mathrm{Cr}$ - creatinine, DPPH - 1,1-diphenyl-2-picrylhydrazyl, HDL - high density lipoprotein, HMGR - HMG-CoA reductase, HPLC-DAD/MSD - high-performance liquid chromatography with diode array and mass spectrometry detection, GAE - gallic acid equivalents, LDL - low density lipoprotein, MDA - malondialdehyde, SOD - superoxide dismutase, SREBP1c sterol regulatory element binding protein-1c, TAC - total antioxidant capacity, TC - total cholesterol, TG - triglyceride.

Acknowledgements. - This work was supported by a grant from Thammasat University, Thailand, under grant number: TP 2/41/2014. The authors acknowledge Dr. Pholawat Tingpej and Mr. Sebastien Maury for their help in proofing and editing the manuscript.

\section{REFERENCES}

1. K. B. Pandey and S. I. Rizvi, Plant polyphenols as dietary antioxidants in human health and disease, Oxid. Med. Cell Longev. 2 (2009) 270-278; https://doi.org/10.4161/oxim.2.5.9498

2. S. J. Nicholls, E. M. Tuzcu, I. Sipahi, A. W. Grasso, P. Schoenhagen, T. Hu, K. Wolski, T. Crowe, M. Y. Desai, S. L. Hazen, S. R. Kapadia and S. E. Nissen, Statins, high-density lipoprotein cholesterol, and regression of coronary atherosclerosis, JAMA 297 (2007) 499-508; https://doi.org/10.1001/ jama.297.5.499 
3. M. P. Sajan, M. L. Standaert, S. Nimal, U. Varanasi, T. Pastoor, S. Mastorides, U. Braun, M. Leitges and R. V. Farese, The critical role of atypical protein kinase C in activating hepatic SREBP-1c and NFkappaB in obesity, J. Lipid Res. 50 (2009) 1133-1145; https://doi.org/10.1194/jlr.M800520-JLR200

4. O. Avoseh, O. Oyedeji, P. Rungqu, B. Nkeh-Chungag and A. Oyedeji, Cymbopogon species; ethnopharmacology, phytochemistry and the pharmacological importance, Molecules 20 (2015) 74387453; https://doi.org/10.3390/molecules20057438

5. M. L. McCullough, J. J. Peterson, R. Patel, P. F. Jacques, R. Shah and J. T. Dwyer, Flavonoid intake and cardiovascular disease mortality in a prospective cohort of US adults, Am. J. Clin. Nutr. 95 (2012) 454-464; https://doi.org/10.3945/ajcn.111.016634

6. K. Wolfe, X. Wu and R. H. Liu, Antioxidant activity of apple peels, J. Agric. Food Chem. 51 (2003) 609-614; https://doi.org/10.1021/jf020782a

7. C. C. Chang, M. H. Yang, H. M. Wen and J. C. Chern, Estimation of total flavonoid content in propolis by two complementary colorimetric methods, J. Food Drug Anal. 10 (2002) 178-182.

8. A. Duangjai, N. Limpeanchob, K. Trisat and D. Amornlerdpison, Spirogyra neglecta inhibits the absorption and synthesis of cholesterol in vitro, Integr. Med. Res. 5 (2016) 301-308; https://doi. org/10.1016/j.imr.2016.08.004

9. M. Okawa, J. Kinjo, T. Nohara and M. Ono, DPPH (1,1-diphenyl-2-picrylhydrazyl) radical scavenging activity of flavonoids obtained from some medicinal plants, Biol. Pharm. Bull. 24 (2001) 12021205.

10. H. H. Draper, E. J. Squires, H. Mahmoodi, J. Wu, S. Agarwal and M. Hadley, A comparative evaluation of thiobarbituric acid methods for the determination of malondialdehyde in biological materials, Free Radic. Biol. Med. 15 (1993) 353-363.

11. C. K. Roberts, K. Liang, R. J. Barnard, C. H. Kim and N. D. Vaziri, HMG-CoA reductase, cholesterol 7a-hydroxylase, LDL receptor, SR-B1, and ACAT in diet-induced syndrome X, Kidney Int. 66 (2004) 1503-1511; https://doi.org/10.1111/j.1523-1755.2004.00914.x

12. X. Rong, Y. Li, K. Ebihara, M. Zhao, T. Kusakabe, T. Tomita, M. Murray and K. Nakao, Irbesartan treatment up-regulates hepatic expression of PPARalpha and its target genes in obese Koletsky $(\mathrm{fa}(\mathrm{k}) / \mathrm{fa}(\mathrm{k}))$ rats: a link to amelioration of hypertriglyceridaemia, Br. J. Pharmacol. 160 (2010) 17961807; https://doi.org/10.1111/j.1476-5381.2010.00835.x

13. S. L. Patil, S. H. Mallaiah and R. K. Patil, Antioxidative and radioprotective potential of rutin and quercetin in Swiss albino mice exposed to gamma radiation, J. Med. Phys. 38 (2013) 87-92; https:// doi.org/10.4103/0971-6203.111321

14. T. A. Abd El-Aziz, R. H. Mohamed, H. F. Pasha and H. R. Abdel-Aziz, Catechin protects against oxidative stress and inflammatory-mediated cardiotoxicity in adriamycin-treated rats, Clin. Exp. Med. 12 (2012) 233-240; https://doi.org/10.1007/s10238-011-0165-2

15. M. Dobiasova and J. Frohlich, The plasma parameter log (TG/HDL-C) as an atherogenic index: correlation with lipoprotein particle size and esterification rate in apoB-lipoprotein-depleted plasma (FER(HDL)), Clin. Biochem. 34 (2001) 583-588.

16. S. Almoosawi, L. Fyfe, C. Ho and E. Al-Dujaili, The effect of polyphenol-rich dark chocolate on fasting capillary whole blood glucose, total cholesterol, blood pressure and glucocorticoids in healthy overweight and obese subjects, Br. J. Nutr. 103 (2010) 842-850; https://doi.org/10.1017/ S0007114509992431

17. L. Anila and N. R. Vijayalakshmi, Beneficial effects of flavonoids from Sesamum indicum, Emblica officinalis and Momordica charantia, Phytother. Res. 14 (2000) 592-595.

18. B. Enkhmaa, K. Shiwaku, T. Katsube, K. Kitajima, E. Anuurad, M. Yamasaki and Y. Yamane, Mulberry (Morus alba L.) leaves and their major flavonol quercetin 3-(6-malonylglucoside) attenuate atherosclerotic lesion development in LDL receptor-deficient mice, J. Nutr. 135 (2005) 729-734.

19. C. Bursill, P. D. Roach, C. D. Bottema and S. Pal, Green tea upregulates the low-density lipoprotein receptor through the sterol-regulated element binding protein in HepG2 liver cells, J. Agric. Food Chem. 49 (2001) 5639-5645. 
20. P. S. M.Prince and N. K. Kannan, Protective effect of rutin on lipids, lipoproteins, lipid metabolizing enzymes and glycoproteins in streptozotocin-induced diabetic rats, J. Pharm. Pharmacol. 58 (2006) 1373-1383; https://doi.org/10.1211/jpp.58.10.0011

21. A. Ziaee, F. Zamansoltani, M. Nassiri-Asl and E. Abbasi, Effects of rutin on lipid profile in hypercholesterolaemic rats, Basic Clin. Pharmacol. Toxicol. 104 (2009) 253-258; https://doi. org/10.1111/j.1742-7843.2008.00368.x

22. R. Zhang, Y. Yao, Y. Wang and G. Ren, Antidiabetic activity of isoquercetin in diabetic KK $-\mathrm{A}^{\mathrm{y}}$ mice, Nutr. Metab. (London) 8 (2011) Article ID 85 (6 pages); https://doi.org/10.1186/1743-7075-8-85

23. E. Ginter and V. Simko, Statins: the drugs for the 21st century?, Bratisl. Lek. Listy 110 (2009) 664668.

24. J. Moon, S. M. Lee, H. J. Do, Y. Cho, J. H. Chung and M. J. Shin, Quercetin up-regulates LDL receptor expression in HepG2 cells, Phytother. Res. 26 (2012) 1688-1694; https://doi.org/10.1002/ptr.4646

25. C. H. Wu, M. C. Lin, H. C. Wang, M. Y. Yang, M. J. Jou and C. J. Wang, Rutin inhibits oleic acid induced lipid accumulation via reducing lipogenesis and oxidative stress in hepatocarcinoma cells, J. Food Sci. 76 (2011) T65-T72; https://doi.org/10.1111/j.1750-3841.2010.02033.x

26. N. Chen, R. Bezzina, E. Hinch, P. A. Lewandowski, D. Cameron-Smith, M. L. Mathai, M. Jois, A. J. Sinclair, D. P. Begg, J. D. Wark, H. S. Weisinger and R. S. Weisinger, Green tea, black tea, and epigallocatechin modify body composition, improve glucose tolerance, and differentially alter metabolic gene expression in rats fed a high-fat diet, Nutr. Res. 29 (2009) 784-793; https://doi. org/10.1016/j.nutres.2009.10.003

27. V. Francisco, A. Figueirinha, G. Costa, J. Liberal, M. C. Lopes, C. García-Rodríguez, C. F. G. C. Geraldes, M. T. Cruz and M. T. Batista, Chemical characterization and antiinflammatory activity of luteolin glycosides isolated from lemongrass, J. Funct. Foods 10 (2014) 436-443; https://doi. org/10.1016/j.jff.2014.07.003

28. J. F. Liu, Y. Ma, Y. Wang, Z. Y. Du, J. K. Shen and H. L. Peng, Reduction of lipid accumulation in HepG2 cells by luteolin is associated with activation of AMPK and mitigation of oxidative stress, Phytother. Res. 25 (2011) 588-596; https://doi.org/10.1002/ptr.3305

29. G. C. Ness, C. M. Chambers and D. Lopez, Atorvastatin action involves diminished recovery of hepatic HMG-CoA reductase activity, J Lipid Res. 39 (1998) 75-84.

30. F. Borthwick, R. Mangat, S. Warnakula, M. Jacome-Sosa, D. F. Vine, and S. D. Proctor, Simvastatin treatment upregulates intestinal lipid secretion pathways in a rodent model of the metabolic syndrome, Atherosclerosis 232 (2014) 141-418; https://doi.org/10.1016/j.atherosclerosis.2013.10.031 